\title{
Application of Cohesion Theory in CET-4 Listening Comprehension
}

\author{
Chunxia $\mathrm{Fu}^{1}$ \\ ${ }^{1}$ Faculty of Foreign Studies, Yangtze University College of Arts and Sciences, Jingzhou, Hubei, China, 434020 \\ Correspondence: Chunxia Fu, Faculty of Foreign Studies, Yangtze University College of Arts and Sciences, \\ Jingzhou, Hubei, China.
}

Received: October 23, 2021

Accepted: November 4, 2021

Online Published: November 11, 2021

doi: $10.5539 /$ elt.v14n12p18

URL: https://doi.org/10.5539/elt.v14n12p18

\begin{abstract}
Cohesion is a very important part of learning English. The Cohesion Theory of Halliday and Hasan is of great importance for people to acquire the knowledge of cohesion. This study is aimed at applying this Cohesion Theory in CET-4 listening comprehension which is an important test for Chinese college students. This study uses the test papers of CET-4 in June 2021 as examples to demonstrate that it is obvious that there are certain cohesive relations between the listening materials and the correct answers. It is also practicable to apply the Cohesion Theory in listening comprehension of CET-4. It mainly analyzes the cohesive devices applied in figuring out the correct choices by understanding the cohesive relations between the listening materials with the right answers. It demonstrated obviously that there exists the cohesive relations between the listening materials with the right answers in the test, and both the grammatical device and lexical device are often used interactively. The cohesive devices can serve as the important clues for students to make the right choices. The findings of this study suggest that the application of the Cohesion Theory in CET-4 listening comprehension is practicable and effective. It can not only help the students get good performance in the CET-4 tests, the same approach can also be used in other important tests.
\end{abstract}

Keywords: Cohesion Theory, listening comprehension, CET-4, China

\section{Introduction}

CET-4 (College English Test Band 4) is a very important test for Chinese college students, and listening comprehension is one of the four parts in the test, which accounts for $35 \%$ in the whole test scores. While its significance is obvious, students' scores of listening comprehension are usually lower compared with the reading comprehension which has the same proportion as the listening part in the test. As is commonly known that the listening abilities can't be improved quickly in a very short time, so further research on how to improve students' listening abilities and listening comprehension in CET-4 is quite urgent.

This study is aimed at demonstrating the cohesive relations between the listening materials with the correct answers with the analysis of abundant examples in the latest CET-4 tests. This study, based upon the Cohesion Theory of Halliday and Hasan, is applying the cohesive devices for the listening comprehension of CET-4. It proves that the cohesive devices are manifest and effective in the listening part of the test and presents the practical importance of using the Cohesion Theory in the listening part of both CET-4 and college English teaching.

\section{Cohesion Theory}

The theoretical basis of this research is the Cohesion Theory of Halliday and Hasan. In their book Cohesion in English, cohesion is mainly divided into two categories. The first one is grammatical cohesion and the second one is lexical cohesion. Reference, substitution, ellipsis and conjunction are the four kinds included in the grammatical cohesion. While reiteration and collocation are the two kinds included in the lexical cohesion.

According to the Cohesion Theory of Halliday and Hasan, the words usually make reference to something else, so it is important to identify the reference in the text. Reference indicates that an element in the text has relation with something else that is in the same text. As for the types of reference, there are personal reference, demonstrative reference and comparative reference. Substitution is a replacement of one item by another, which can be the words or the phrases. The substitute one may have the same function as a noun, a verb or a clause, so they are the corresponding three different kinds of substitution. Ellipsis means omitting a word or certain part of a sentence in a text. Even though there is something unsaid, it may have the implication that it has been 
understood. The omission parts are usually nouns, verbal phrases and clauses. Conjunction does not have cohesion itself but it indicates cohesion indirectly by the virtue of the specific meaning. An approach to obtain cohesion with vocabulary selection is called the lexical cohesion. Selecting the words, phrases or other items that are indicating to what have been mentioned before will make the text more integrated. Reiteration is a lexical device which refers to repeating the lexical items, which can be the same word, synonym, a superordinate or a general word. Collocation has to do with the relationship between words on that they often occur in the same context. It includes not only the synonyms and superordinates, but also different pairs of opposites, antonyms and converses.

In the listening comprehension, the more easily the students identify the cohesive relations between what they have heard with the printed choices, the more likely they are to choose the correct ones and the higher scores they will get in the tests.

\section{Characteristics of CET-4 Listening Comprehension}

There are two times for CET-4 test each year (usually in June and December), and there are three CET-4 test papers each time, with different materials but in sample models of the test parts. As for the listening comprehension, there are only two sets.

There are three parts of the CET-4 listening comprehension. The three parts are three news reports in section A, two long conversations in section B and three passages in section $\mathrm{C}$ respectively. As in the total scores, section A accounts for $7 \%$, section B accounts for $8 \%$ and section C accounts for $20 \%$. All of the questions are in the form of the multiple-choice questions, and there are 7 questions in section A ( 2 or 3 questions for each news report), 8 questions in section B (4 questions for each conversation), and 10 questions in section C ( 3 or 4 questions for each passage). All the recording materials and questions are spoken only once.

The CET-4 test requires students to understand short English news reports in relatively slow speed, to understand simple English conversations with familiar topics and understand long speeches or reports in the slow speed and familiar subjects. The students should also use basic listening strategies to help understand the listening materials. The students' abilities of figuring out the main idea, getting important facts and details, knowing the implications and the speaker's opinions or attitudes are highly needed.

\section{Application of Cohesion Theory in CET-4 Listening Comprehension}

This part mainly analyzes the corresponding relations between the listening scripts with the choices based on the Cohesion Theory. All the examples below are from the CET-4 test papers in June 2021.

\subsection{Application of Cohesion Theory in News Report Listening}

News report understanding is the first part in the listening comprehension. The feature of it is that it has the structure of "inverted pyramid", as the beginning part is the most important part which states the information of "who, what, where, when, why and how". This part is very difficult for students because most of them can't focus on listening at the very beginning, so they usually skip the important information of the news report. In addition, there are many proper names or terms with which the students are not very familiar. As for these two main reasons, the students don't get high grades in this part. However, if the students can try to identify the cohesive relations between the information they hear with the choices, they may get them matched. This may be a practicable approach and worth conducting.

Table 1. News Report Two in CET-4 Test Paper (1) in June 2021

\begin{tabular}{|c|c|}
\hline \multicolumn{2}{|l|}{ Question 3} \\
\hline Audio Scripts & $\begin{array}{l}\text { Christine Marshall, a-34-year-old mum of one posted a tearful video on social media, } \\
\text { Wednesday, begging for the safe return of her beloved pet dog. }\end{array}$ \\
\hline Correct Answer & A) Get her pet dog back. \\
\hline \multirow[t]{2}{*}{ Cohesive devices } & Reiteration-using a synonym \\
\hline & Reiteration-repeating the same word \\
\hline \multicolumn{2}{|l|}{ Question 4} \\
\hline Audio Scripts & $\begin{array}{l}\text { The family is now offering a } 5,000 \text { pound reward for the safe return of the dog after } \\
\text { launching a social media campaign to find the thief. }\end{array}$ \\
\hline Correct Answer & D) It is offering a big reward to anyone who helps. \\
\hline Cohesive devices & Reiteration-using a general word \\
\hline
\end{tabular}


As we can see in Table 1, the lexical device of reiteration can be used in this news report. According to Halliday and Hasan, there are mainly four types of reiterations which are repeating the same word, using a synonym or near-synonym, using a superordinate and using a general word. Here, repeating the same word and using a synonym are both used in Question 3. As "her pet dog" is the same word repeated and "return" is similar to "give it back". In Question 4, the major information is "offering a 5,000 pound reward", and it correlates with "offering a big reward" in the choice D. Using a general word is applied here, as "5,000 pound" is a much specific number and "big" is general.

As is analyzed above, the cohesive device of reiteration is mainly applied in this news report. Using a synonym and using a general word are useful for identifying the correct choices. If the students are taught about these cohesive devices, they will be more likely to catch the right answers.

\subsection{Application of Cohesion Theory in Long Conversation Listening}

Long conversations are usually about the daily topics in our life. The subject sentence is often at the beginning of the conversation, and it actually suggests the topic of the whole conversation. In the long conversation, it is usually in the model of question and answer, so it is important to catch the answers of the two speakers. The questions after the long conversation are highly related to the answers of the speakers in the conversation.

Table 2. Conversation One in CET-4 Test Paper (1) in June 2021

\begin{tabular}{|c|c|}
\hline Question 8 & \\
\hline \multirow[t]{3}{*}{ Audio Scripts } & So what time do you think we should have the party on Saturday? \\
\hline & What food should we provide? \\
\hline & What should we do about music? \\
\hline Correct Answer & C) Preparations for Saturday's get-together. \\
\hline \multirow{3}{*}{ Cohesive devices } & Conjunction \\
\hline & Reiteration-repeating the same word \\
\hline & Reiteration--using a synonym \\
\hline \multicolumn{2}{|l|}{ Question 9} \\
\hline Audio Scripts & It's better to let people walk around and talk to each other or sit where they like. \\
\hline Correct Answer & B) It enables guests to walk around and chat freely. \\
\hline \multirow[t]{3}{*}{ Cohesive devices } & Reference-comparative reference \\
\hline & Reiteration-repeating the same word \\
\hline & Reiteration-using a synonym \\
\hline \multicolumn{2}{|l|}{ Question 10} \\
\hline Audio Scripts & $\begin{array}{l}\text { And I heard that the new supermarket offers some big discounts to attract } \\
\text { customers, so going there should be a great idea. }\end{array}$ \\
\hline Correct Answer & A) It offers some big discounts. \\
\hline \multirow[t]{2}{*}{ Cohesive devices } & Conjunction-causal conjunction \\
\hline & Reiteration-repeating the same word \\
\hline \multicolumn{2}{|l|}{ Question 11} \\
\hline Audio Scripts & $\begin{array}{l}\text { Maybe we should also ask Paul to bring his computer and speakers so that we } \\
\text { can play some music. }\end{array}$ \\
\hline Correct Answer & D) Bring his computer and speakers. \\
\hline \multirow[t]{2}{*}{ Cohesive devices } & Conjunction-causal conjunction \\
\hline & Reiteration-repeating the same word \\
\hline
\end{tabular}

In Table 2, both the grammatical and lexical devices are used. At the beginning, the speaker is asking about the exact time they have the party on Saturday. The word "Saturday" is the same word repeated in the choice C, and repeating the same word in reiteration is applied here. What's more, "the party" also refers to "get-together", the devices of using a synonym in reiteration is used here. The following questions about the time and music are all the important parts of the party, and they suggest the indication of systematic relation. So the conjunction is also used here, as it can help the students to get a party preparation in a very logical order. Question 8 asks about 
what the two speakers mainly talk about, if the students know the cohesive devices of the conjunction and reiteration, understanding the time, food and music are all the important parts for party preparation, then it can be much easier for them to choose the correct choice $\mathrm{C}$.

Other three questions are about the details of the conversation. In Question 9, both the reference and reiteration are used here. The phrase "walk around" is repeated exactly the same, and "talk to each other" is similar to "talk freely". Meanwhile, the sentence pattern "It's better to ..." suggests the comparative reference. The speaker thinks it is a good idea to prepare some food so that people can just help themselves instead of sitting down at the table to eat a meal. In Question 10, "offers some big discounts" is repeated the same in the choice B, and the conjunction "so" served as the causal conjunction to explain the reason of going to the new supermarket. Question 11 also has the same cohesive devices as Question 10. The expression "bring his computer and speakers" is the same repeated here, and "so that" as the conjunction suggests the reason of asking Paul to bring his computer and speakers.

As analyzes in this part, the cohesive devices, whether they are grammatical ones or lexical ones, can be applied interactively, and they all are useful not only for the students to identify the correct choices, but also for the comprehensive understanding of the listening materials.

\subsection{Application of Cohesion Theory in Passage Listening}

Passages of the listening part in CET-4 tests usually covers a lot of information with extensive subjects, which may include daily life phenomena, recent scientific findings, experiments and researches, stories of famous people or social problems. Besides, there are often some long and difficult sentences in the passages, which makes it hard for students to understand the materials. However, some cohesive devices can be identified and applied to help the students to match the recording with the right choice.

Table 3. Passage Two in CET-4 Test Paper (2) in June 2021

\begin{tabular}{|c|c|}
\hline \multicolumn{2}{|l|}{ Question 19} \\
\hline Audio Scripts & $\begin{array}{l}\text { And now, the World Health Organization has recognized addiction to } \\
\text { computer games as a disease. }\end{array}$ \\
\hline Correct Answer & B) Addiction to computer games is a disease. \\
\hline \multirow[t]{2}{*}{ Cohesive devices } & Conjunction- continuative conjunction \\
\hline & Reiteration-repeating the same word \\
\hline \multicolumn{2}{|l|}{ Question 20} \\
\hline Audio Scripts & $\begin{array}{l}\text { Such people make computer games a priority over their responsibilities. They } \\
\text { may play games instead of attending school, or work, or socializing. }\end{array}$ \\
\hline Correct Answer & A) They prioritize their favored activity over what they should do. \\
\hline \multirow[t]{2}{*}{ Cohesive devices } & Reference-comparative reference \\
\hline & Reiteration-using a general word \\
\hline \multicolumn{2}{|l|}{ Question 21} \\
\hline Audio Scripts & $\begin{array}{l}\text { Still not all behavior experts agree. Some argue that there's not enough } \\
\text { research on the subject. Thus, they claim it is too early to call computer game } \\
\text { addiction a disorder. }\end{array}$ \\
\hline Correct Answer & C) There is not enough evidence to classify it as a disease. \\
\hline \multirow[t]{2}{*}{ Cohesive devices } & Conjunction-causal conjunction \\
\hline & Reiteration-using a synonym \\
\hline
\end{tabular}

As is shown in Table 3, the passage is a discussion about whether addiction to computer games is a disease or not. In Question 19, the expression "And now" suggests the cohesion of continuative conjunction, which leads what the World Health Organization has recently recognized, and "addiction to computer games" and "a disease" are the same words repeated here, so the lexical device of reiteration is used here. Reference and reiteration are applied in Question 20. "Such people" refers to the people with addictive behavior to computer games, since they are addicted to computer games, playing computer games is their favored activity. The words "priority" and "prioritize" are different parts of speech, the meaning they suggest is actually the same. And "what they should do" in the Choice A is generalized as "their responsibilities" in the recording. Reiteration of using a general word is applied in this part. So with the cohesive devices of reference and reiteration, the correct 
answer A can be easily identified. In Question 21, "Thus" suggests the causal conjunction of the two sentences. Because there is not enough research evidence, computer game addiction can not be classified as disease. The word "disorder" refers to an illness that causes a part of the body to stop functioning correctly. It is similar to "disease". So the reiteration of using a synonym is applied here.

As is mentioned in this part, a lot of cohesive devices are indicated, whether they are grammatical devices or lexical devices. Both of these two kinds of devices are frequently used for the passage listening comprehension. Having a solid foundation of the comprehensive cohesion theory and cohesive devices is preferable for the students to perform better in the listening comprehension.

The test papers of CET-4 in June 2021 are discussed here as examples to show that the listening comprehension can be analyzed under the theory of Cohesion Theory. It suggests that listening comprehension of other CET-4 tests can also be analyzed under the guidance of this theory.

\section{Conclusion}

With the above discussion and analysis, it is obvious for us to know that there are a lot of cohesive relations between the listening materials and the correct choices. Thus, the Cohesion Theory can be applied in CET-4 listening comprehension. That may be an effective approach to the CET-4 listening comprehension. It may also provide a new perspective and a new attempt for college English teaching. This approach can not only make the listening materials and answers more targeted, but it also increases the probability for the students choosing the correct answers and improves their test scores. It also suggests that the students should have a good command of the Cohesion Theory and know the comprehensive cohesive devices, and they should also know that the cohesive grammatical devices and lexical devices are not always used alone; instead they are often applied interactively. If the students know well about the cohesive devices, they can easily identify them used in the listening comprehension and match the correct answers.

Meanwhile, the fact that the Cohesion Theory can be applied to CET-4 listening comprehension can also be effective for the listening comprehension of other kinds of tests such as CET-6, TEM-4 (Test for English Majors Band 4) or TEM-8 (Test for English Majors Band 8).

The introduction and significance of applying the Cohesion Theory to CET-4 listening comprehension is mainly discussed in this article, and the practice of the application in teaching is to be carried out to consolidate the research in the near future.

\section{References}

Chunxia Fu. (2020). Application of Cohesion Theory in Reading Comprehension of CET-4. English Language Teaching, 13, 86-90. https://doi.org/10.5539/elt.v13n4p86

Esther Geva, \& Fataneh Farnia. (2012). Developmental Changes in the Nature of Language Proficiency and Reading Fluency Paint a More Complex View of Reading Comprehension in ELL and EL1. Reading and Writing, 25(8), 1819-1845. https://doi.org/10.1007/s11145-011-9333-8

Halliday, M. A. K., \& Hasan, R. (1976). Cohesion in English. London: Longman.

Johnson, K. (2002). An Introduction to Foreign Language Learning and Teaching. Beijing: Foreign Language Teaching and Research Press.

Katya Goussakova. (2016). Teaching and Learning English Grammar: Research Findings and Future Directions. System, 59, 133-135. https://doi.org/10.1016/j.system.2016.04.012

Krashen, S. (1981). Second Language Acquisition and Second Language Learning. Oxford: Pergamon Press.

\section{Copyrights}

Copyright for this article is retained by the author(s), with first publication rights granted to the journal.

This is an open-access article distributed under the terms and conditions of the Creative Commons Attribution license (http://creativecommons.org/licenses/by/4.0/). 